\title{
Formas, temas, verbos: encarnaciones de la poesía en Los detectives salvajes, de Roberto Bolaño
}

\author{
ORIELE BENAVIDES Universidad de Princeton, Estados Unidos \\ ORCID 0000-0002-4016-366X \\ osalazar@princeton.edu
}

\section{Resumen}

El trabajo describe y analiza la consistencia intensamente corpórea que cobra la presencia de la poesía, en la primera parte de la novela Los detectives salvajes, del escritor Roberto Bolaño, a partir de tres ejes: la escenificación del falso diario del joven poeta García Madero, en el que se replican escenas también ocurrentes en la poesía que Bolaño escribía para la época, en un registro, por el contrario, vitalizado. Segundo, la temática aludida de los poemas que él junto a sus colegas realvisceralistas escriben, y, por último, el efecto (visceral, escatológico, urgente) que la lectura y la escritura de esos poemas parecen tener en los personajes que los leen. Así, se propone un ejercicio de Close Reading en el que se exhiben las peripecias alrededor de García Madero, en diálogo con otros momentos de la narrativa y de la poesía del mismo Bolaño, en su calidad de alegoría del poeta como cuerpo viviente, del cual emanará una poesía también viva.

Palabras clave: diario / poesía / cuerpo / Roberto Bolaño / Los detectives salvajes

\section{Forms, Themes, Verbs: Incarnations of Poetry in Los detectives salvajes, by Roberto Bolaño Abstract}

The work describes and analyzes the intensely corporeal consistency that the presence of poetry charges, in the first part of the novel Los detectives salvajes, by the writer Roberto Bolaño, based on three axes: the staging of the false diary of the young poet García Madero, in which scenes also occurring in the poetry that Bolaño wrote for the time are replicated, in a register, on the contrary, vitalized. Second, the subject matter of the poems that he and his realvisceralist colleagues write, and, finally, the effect (visceral, eschatological, urgent) that the reading and writing of those poems seem to have on the characters who read them. Thus, a Close Reading exercise is proposed in which the vicissitudes surrounding García Madero are exhibited, in dialogue with other moments in the narrative and poetry of Bolaño himself, as an allegory of the poet as a living body, of which It will emanate a poetry also alive.

Key words: diary / poetry / body / Roberto Bolaño / Los detectives salvajes

Recibido: 11/6/2020. Aceptado: 19/8/2020

Para citar este artículo: Benavides, O. (2020). Formas, temas, verbos: encarnaciones de la poesía en Los detectives salvajes, de Roberto Bolaño. El taco en la brea, 12 (junio-noviembre). Santa Fe, Argentina: UNL. eoo15 DOI: 10.14409/tb.v1i12.9693 
He sido invitado a formar parte del realismo visceral. Por supuesto, he aceptado. (...) No sé muy bien en qué consiste el realismo visceral. Tengo diecisiete años, me llamo Juan García Madero (...). Soy huérfano. Seré abogado. Eso le dije a mi tío y a mi tía y luego me encerré en mi habitación y lloré toda la noche.

Roberto Bolaño

Con estas palabras, extraídas del diario del joven Juan García Madero, se inicia la que será la primera parte de Los detectives salvajes: el aspirante a poeta nos presentará abruptamente su vida, desde el momento en el que se encuentra con el grupo poético de los realvisceralistas, el 2 de noviembre de 1975, hasta la atrabiliaria cena de año nuevo que tendrá lugar en casa de las hermanas Font de la colonia Condesa, uno de los escenarios privilegiados de la narración durante este segmento de la novela, titulado «Mexicanos perdidos en México (1975)». A través del relato del día a día en el que se adentra en la manada de los desacompasados vanguardistas autodenominados realvisceralistas, seguiremos al narrador, en lo que constituirá, a la vez que una frenética educación sentimental, su propia temporada en el inferno del DF Mexicano. Así, durante dos meses, las peripecias se sucederán sin descanso y, para el ojo de García Madero, al menos, todo será extraordinario, maravilloso o terrible, terrorífico: disputas y escisiones grupales en talleres de escritura, interminables cafés con leche en el café Quito o en la Encrucijada Veracruzana de la calle Bucareli, fiestas en cuya bruma sórdida se narran extravagantes anécdotas literarias, primeros encuentros sexuales y amores incipientes, listas de las lecturas por hacer permanentemente actualizadas, tránsitos por las librerías de la ciudad en las que García Madero compra o roba aquello que está a su alcance, y, finalmente, la huida de la ciudad escapando del proxeneta de la jovencísima Lupe, acompañado por ella, Belano y Lima, en horas de la madrugada del primero de enero de 1976.

Este «no saber muy bien en qué consiste el realismo visceral» mencionado por García Madero en su intervención inaugural es un aspecto sobre el que vale la pena detenerse, en la medida en que como desconocimiento, como enigma y como interrogante será una nebulosidad interrogada a lo largo de todo el relato. ¿Quiénes son estos poetas y de qué manera entienden y experimentan la vivencia de la poesía? ¿Qué clase de relación entre la literatura y la vida postulan? Las siguientes preguntas podrían ayudarnos en este despeje, y serán aquellas que orientarán el desarrollo de esta lectura: ¿qué implicaciones posee la elección del diario como forma narrativa y, más aún, como forma del retrato literario? ¿Cuáles serán los temas de esta poesía presente a lo largo de toda la narración, de qué experiencias abreva? ¿Qué efectos persigue o detona esta poesía real y que atañe al cuerpo y a su dimensión más visceral?

\section{Formas: los diarios de un joven poeta, o retrato de un poeta en movimiento}

Los detectives salvajes se enmarca en un proyecto escritural más amplio, que parece encontrar en los esbozos de tintes biográficos una de sus formas privilegiadas de indagación creativa. Así, Roberto Bolaño reelaboró, en su prosa y en su poesía, sus obsesiones memoriosas, haciendo de ellas la materia prima de su producción escrita, y utilizando el retrato y el autorretrato de artista como posibilidad de composición poética: bajo la forma del monólogo alucinado en Amuleto y Nocturno de Chile, de la parodia enciclopédica en La literatura nazi en América, del listado delirante en «Carnet de Baile» o de la fabulación onírica en «Encuentro con Enrique Lihn», anclándose en la fábula animal de tintes kafkianos y alegóricos en «Pepe el tira», o reescribiendo clásicos de la tradición cuentística latinoamericana en el borgiano «El gaucho insufrible», entre muchos otros 
ejemplos que proporciona el universo de este escritor. Sin embargo, aspectos de forma, de tono y de registro singularizan lo mostrado en la novela que nos concierne, empezando por el recurso al diario, del que solo parece hacer uso en Los detectives...

Podríamos decir que el diario, como una suerte de geografía de la existencia, es en primera instancia una forma de recuperación del sentido de la propia vida, de unificación del desperdigamiento de unos trazos que testimonian un recorrido vital, cohesionado en la escritura diarística alrededor del nombre propio y del regular registro del paso del tiempo. Entre la afirmación narcisística del propio yo y la ambición, la nostalgia o el anhelo de destino, se percibe la naturaleza de este género voluble e impreciso: más que en la sustancia de aquello rubricado en el diario, ya que el formato admite cualquier tipo de material (afirma Piglia en el suyo — 2016:7-8—), la confirmación del género o su esencia estaría en la disposición de aquellos según una serialidad fechada, para «orientarse en el torrente del tiempo» (7), junto con la garantía, provisional o no, proporcionada por el nombre singular. Este otorga un cierto pacto de autenticidad: a quien consigna sus experiencias en un diario, además de suponérsele una identidad estable a lo largo del relato, se le presume cierta espontaneidad o sinceridad, y se le toleran incluso ciertas banalidades ligadas a la cotidianidad que enmarca este tipo de escritura.

El diario es, entonces, un género que problematiza el paso del tiempo en relación con la vida íntima del sujeto diarista, y presupone una cierta veracidad ligada a lo mundano, lo común, lo ordinario y lo espontáneo. Esta «sucesión periódica de vivencias expresada en forma de fragmentos», según la definición del narrador peruano Julio Ramón Ribeyro, también presenta una cierta tonalidad existencial recurrente: «el sentimiento de inseguridad, de incertidumbre y de desamparo que palpita en todo auténtico diario íntimo» (2012:29). En términos de estructura y estilo, Ribeyro insiste en este «sentido del fragmento» que poseen los diaristas, entendido como tendencia a la brevedad o la inclinación por una clara condensación de la experiencia. Veracidad, cotidianidad, fragmento y desamparo serían pues los cuatro pilares de este género literario: el escritor peruano no titubea en llamarlo así, y como dato curioso podemos agregar que su diario (La tentación del fracaso -2002-), uno de los más relevantes de la literatura latinoamericana del siglo XX, también empieza con la desazón cara a su destino de abogado, en contradicción con su vocación de escritor.

El día elegido por Bolaño para dar inicio a su narración es el 2 de noviembre, fecha de la primera entrada del diario de García Madero, y coincide, en afinidad con el epígrafe de Malcolm Lowry que encabeza Los detectives..., con la jornada en la que transcurren la mayoría de los acontecimientos narrados en Bajo el volcán (1947), novela visceral si las hay. Esta obra norteamericana está ambientada en Cuernavaca, México, y en ella la exigencia rimbaudiana de desarreglar los sentidos para acceder a un plano en el que la literatura en su expresión más pura y real sería posible, toma una forma bastante rotunda. De esta manera, el Cónsul, su protagonista, pasa toda la novela ebrio y alucinado, de forma análoga aunque no idéntica a la exacerbación sensorial y corporal, que determinará los intercambios entre García Madero y la realidad que registrará en sus escritos.

El 2 de noviembre es también, como sabemos, el Día de Muertos, fecha emblemática de la cultura mexicana en la que se conmemora la presencia de los antepasados familiares y se les visita. Al igual que en Bajo el volcán, la fecha también resuena en su coincidencia con el desenlace de la Batalla del Ebro que marcaría el declive del Ejército Republicano español y la posterior caída de Cataluña hacia el fin de la Guerra Civil española, en el mismo año en que se desarrollan los acontecimientos de la novela de Lowry. Ninguna de estas correspondencias' resulta en absoluto 
lateral, si pensamos que la inquietud fundamental que sustenta una escritura como la de Los detectives... es la pregunta por los propios espectros: cómo acercarse a ellos, cómo describirlos, cómo relatarlos, cómo volver a ellos. El desamparo frente al «torrente del tiempo», la conciencia entre melancólica e irónica de la derrota política y de las batallas perdidas, y la persistencia ambigua de un recuerdo magmático, quemante (de sus propios Muchachos desnudos bajo el arcoíris de fuego), ${ }^{2}$ es precisamente a lo que parece enfrentarse Bolaño en la escritura de una novela como Los detectives salvajes. La invocación de reintegración a una comunidad, es decir, a la manada de sus años de juventud, a sus propios «años felices» — Piglia dixit-, parece encontrar la forma adecuada para su mostración a través de la irrupción del diario de esta presencia espectral.

Un material de similar textura había sido ya elaborado por el autor a través de su producción poética. En la antología Los perros románticos (2010 [1993]), el poema que le da título la inaugura, impregnando la lectura de todo el artefacto y asentando, quizá, las coordenadas de su imaginario: el sueño, la juventud, la pérdida y el olvido, la soledad presente en contraste con el recuerdo de la pertenencia a la tribu. El poema nos describe el momento pretérito en el que el narrador eligió permanecer en ella:

\footnotetext{
En aquel tiempo yo tenía veinte años/y estaba loco./ Había perdido un país/ pero había ganado un sueño./Y si tenía ese sueño/lo demás no importaba./ Ni trabajar ni rezar/ni estudiar en la madrugada/ junto a los perros románticos./Y el sueño vivía en el vacío de mi espíritu./(...) Y la pesadilla me decía: crecerás./ Dejarás las imágenes del dolor y del laberinto/y olvidarás./ Pero en aquel tiempo crecer hubiera sido un crimen./ Estoy aquí, dije, con los perros románticos/y aquí me voy a quedar. (13; énfasis nuestro)
}

En «El último salvaje» la soledad del narrador es más explícita, y la desolación y cierta perplejidad se unen a la reconstrucción heroica de sí mismo como legatario final de una estirpe cuya memoria se encuentra al borde de la desaparición:

Salí de la última función a las calles vacías (...)/ No tenía dónde ir. Durante mucho tiempo/vagué por los alrededores del cine/ (...) Me vi a mí mismo como El Último Salvaje montado en una motocicleta blanca, recorriendo los caminos/de Baja California. A mi izquierda el mar, a mi derecha/ el mar/y en mi centro la caja llena de imágenes que/ paulatinamente/se iban desvaneciendo. (68-69)

Más adelante, nos toparemos con numerosas escenas en las que el retrato generacional y propio sigue siendo narrado en primera persona, y filtrado por una intensísima fuerza elegíaca que se afinca en la clausura de la experiencia poética («todo ha terminado» - 54-) o en su condición de ruina, de materia inerte: «la poesía verdadera/ ésa que ahora visitan los turistas» («Atole» -75一). Y también del coraje, hermoso pero vano, de quienes la ejercen. De esta manera, en «El burro», se dice: «Acaso son los gestos de valor los que/ nos dicen adiós, sin resentimiento ni amargura (...) resplandor que un día nos atravesó/Y que habíamos olvidado» (78). Y más adelante, en el mismo poema: «Saluda a los fantasmas de nuestra juventud,/ El sueño innombrable e inútil/ de la valentía» (77).

«Entre las moscas» (88) es el último poema del libro, y luce como una especie de epitafio en el que la celebración de la libertad conseguida por la desaparición de la poesía contrasta con la cruda alusión necrológica del título, apenas logrando equilibrar una desazonada melancolía: «Poetas troyanos/Ya nada de lo que podía ser vuestro/ Existe/ Ni templos ni jardines/ Ni poesía/ Sois libres/ Admirables poetas troyanos». 
Como afirma Beatriz Sarlo, «el regreso del pasado no es siempre un momento liberador del recuerdo, sino un advenimiento, una captura del presente» (9). En estos poemas podemos percibir la pregnancia melancólica de lo que quizás es un largo duelo, y la reiteración de los temas y personajes que aparecen en este poemario nos indican el magma del que proviene al menos buena parte de la escritura bolañiana. De hecho, es interesante pensar en la probabilidad de que muchos de los poemas de esta antología hayan sido contemporáneos con la confección de los detectives..., ya que encontramos en ésta analogías explícitas no solo con los temas mencionados, que también forman parte del universo de la novela, aunque en un registro muy distinto. Las embrocaciones llegan al punto de repetir escenas enteras que luego serán incluidas en Los detectives salvajes: en el poema «Lupe», por ejemplo, nos topamos con un retrato bastante similar al que la joven prostituta recibirá en la narración (señalada con el mismo nombre que tomará en la prosa narrativa), mientras que «La visita al convaleciente» replica en muchos aspectos la escena de la visita a casa del poeta Ernesto San Epifanio luego de su trepanación (2017:340-345).

Podemos ver entonces en la elección del diario, como estructura y como formato de la ficción narrativa, una decisión que le permitirá a Bolaño lograr varios efectos distintos a los alcanzados en su lírica. Los privilegios que el género otorga a la voz de la primera persona persisten, al ser esta desplazada a la ficción, impregnando lo relatado de cierta veracidad automática, por más que dicha autenticidad esté mellada por un permanente «desarreglo de los sentidos», y muchas de las acciones resultan brumosas o incomprensibles para la subjetividad del aprendiz de poeta: «En claro no saqué muchas cosas. (...) no sé (...) tampoco lo tengo muy claro (...) pero esto es achacable a mi ignorancia. (...) no lo recuerdo (...) en realidad no entendí nada» (18). Sin embargo, esta mirada adánica, ingenua ( Ay, García Madero, bendita inocencia» -64-), confundida, de un muchacho que es un "compendio de incultura» (104), pero a la vez un «alma pura», de «buen corazón» (157), le permite al autor, por estas precisas características de su dispositivo narrativo, avanzar en la inclusión de acontecimientos y personajes sin que caiga sobre ellos el juicio impuesto por la preterición, como sí ocurre en los poemas donde el narrador parece mucho más cercano, anímica y temporalmente, al Bolaño escritor. Este parece no poder eximirse de ponderar los efectos de la derrota poética y política de su tribu. Por el contrario, la decisión del diario, como formato que ordena la disposición de los materiales, insiste en el propósito que señalamos: consigna lo narrado en el fugaz y cotidiano tempo de su acaecimiento, tiñéndolo simultáneamente de una veraz inestabilidad que resalta su carácter difuso e indescifrado, y avalando (quizás sea esto lo más importante) el despliegue de un entusiasmo todavía incuestionado, genuino: intacto.

El carácter espectral del personaje de García Madero resalta aún más el esfuerzo por construir la voz de un testigo que pueda ser garante de este entusiasmo, como si este intocado y salvaje amor por la poesía no pudiera ser narrado sino por un personaje completamente ficcionado. Es así como durante la atribución de identidades que desencadenó la publicación de Los detectives..., todos los personajes encontraron o fueron reclamados rápidamente por su correlato civil, pero ninguno coincidía del todo con García Madero. ${ }^{3}$ En la fábula, nos topamos con el mismo repertorio agujereado: de esta manera, Ernesto García Grajales, el último entrevistado por los detectives salvajes en su búsqueda de Belano y Lima, pasa listado de los realvisceralistas haciéndonos conocer su destino en el último tiempo de la novela (el año de 1996). Y afirma: «¿Juan García Madero? No, ése no me suena. Seguro que nunca perteneció al grupo. Hombre, si lo digo yo que soy la máxima autoridad en la materia, por algo será» (673). 
Volver al mito de origen omitiendo la severa clausura con la que la derrota es experimentada en Los perros románticos, parece ser el desafío al que se enfrenta Roberto Bolaño; es decir, el responder a la pregunta de cómo recordar al poeta que fue, o al menos cómo recordarlo de otra manera distinta a la oscuridad inmóvil en la que se sitúa el narrador de sus poemas. Así, García Madero literaliza el adagio rimbaudiano (Je est un autre) a través de un personaje que es y no es autobiográfico, y le permite construir una mirada múltiple a la vez que personal, ya transcurrida, preterizada, pero sin embargo anclada en el presente perpetuo de la escritura cotidiana. Es entonces en un doble tiempo como se despliega el diario del joven poeta: el tiempo en el que se leen los diarios de García Madero será a un tiempo el tiempo de la narración, y el tiempo en el que Bolaño recupera ese recuerdo, y quizás de esa manera podríamos interpretar la entrada que corresponde al 1 de enero de 1976 que da pie a la tercera parte de la novela, donde se retoma el diario en un escenario por completo diferente al de las aventuras del inicio: «Hoy me di cuenta de que lo que escribí ayer en realidad lo escribí hoy; (...) Lo que escribo hoy en realidad lo escribo mañana, que para mí será hoy y ayer, y también de alguna manera mañana: un día invisible» (681).

Si las convenciones del género no ficcional alientan a cegar el espacio entre los días y el aburrimiento que necesariamente toda vida comporta con reflexiones, psicologismos e introspecciones, el diario de García Madero revela su naturaleza profundamente ficcional al ser en él aventura todo, todo novedad: los días del diarista se suceden, y lo que en ellos ocurre es «sorprendente», «maravilloso», «extraordinario», o también «brumoso», «confuso», «vago», y a veces «horrible» o «terrorífico». Los adjetivos que acompañan la acción no denotan otra cosa que sorpresa, júbilo, descubrimiento, pánico. Toda ella será peripecia, logrando sostener desde el principio un tono vertiginoso y un ritmo casi inverosímil en el que no parece haber lugar para la indiferencia ni para el descanso. Sus personajes no paran de desplazarse de un lado a otro de la ciudad, de las habitaciones que recorren, de los cafés, como electrificados. La permanente presencia de lo público (la calle, pero también la manada, los otros poetas), el predominio de la ciudad y de los espacios habitados, contradice nuevamente el carácter interior del diario. García Madero hace del tiempo denso, espeso del recuerdo, el tiempo puro y fulminante del presente de la experiencia poética. García Madero no recuerda: es puro presente: un ahora vívido y vigoroso, imbuido de entusiasmo y de furor poético: «Antes no tenía tiempo para nada, ahora tengo tiempo para todo. Vivía montado en camiones y metros, obligado a recorrer la ciudad de norte a sur por lo menos dos veces al día. Ahora me desplazo a pie, leo mucho, escribo mucho, hago el amor cada día» (125-126).

De esta manera, la fluida y frenética felicidad que representa el encuentro con la literatura para el joven García Madero encuentra en el cuerpo presente y continuo del diario la forma que le corresponde, al transformar el material elegíaco presente en los poemas de Roberto Bolaño en el comienzo de una novela de aventuras, bordeando y reconstruyendo en silencio el recuerdo de un poema pretérito. Una novela de aventuras que utiliza la forma de un diario: organizando su experiencia, transmitiendo su sorpresa, permitiendo una distancia paradójica con el propio recuerdo, destellando así su potencia en el tiempo. García Madero es un espejo que huye hacia el presente.

\section{Temas: el resto como experiencia y la experiencia del resto}

De los surrealistas sólo nos puede interesar su programa, que confirma con instrumentos pseudo científicos un modo de hacer poesía inaugurado por Rimbaud. La convicción de que el hombre puede 
ampliar ilimitadamente su experiencia en el caos del inconsciente; la convicción de que el loco, al crear una «sobrerrealidad», no es menos «genial» que el poeta; la concepción de la poesía como un dictado amorfo del inconsciente: éstos son algunos puntos de ese programa. Así se confunde el vómito —incluso poético- con la creación. De ello no resulta ninguna poesía de rango.

Hugo Friedrich

Es harto mencionado el hecho de que Los detectives salvajes sea una novela sobre poetas en la que, sin embargo, no sabemos nada de sus poemas, en el sentido de que las creaciones que escriben los personajes y alrededor de las cuales orbitan, permanente y empecinadamente, no aparecen transcritas en ella, y por lo tanto no pueden ser conocidas por el lector de la novela. Efectivamente, no llegamos a apreciar directamente los poemas que escribirían los realvisceralistas, lo cual, sin embargo, no significa que no jueguen un papel determinante en la consecución de la peripecia y en la estructura de la obra. De esta manera, y de forma análoga a estos personajes de alguna manera espectrales, los poemas también flotan, afantasmados, sobre la trama, y definen en muchos sentidos el comportamiento de los personajes, y con ello el sentido de la narración. Si bien los indicios que denotan algo sobre el carácter de estos poemas no son excesivos, podemos observar a través de ellos el papel clave de la poesía escrita al interior de Los detectives salvajes, y la manera como este papel está determinado por la naturaleza misma de dicha poesía.

Así, al volver a la escena de inicio de la novela, podemos notar cómo el encuentro con la poesía realvisceralista marca un punto sin retorno en la vida de García Madero. Fiel asistente hasta entonces al taller de Julio César Álamo, describe el funcionamiento del mismo con las siguientes palabras:

nunca había ocurrido nada (...) leíamos poemas y Álamo, según estuviera de humor, los alababa o los pulverizaba; uno leía, Álamo criticaba, otro leía, Álamo criticaba, otro más volvía a leer, Álamo criticaba. A veces Álamo se aburría y nos pedía a nosotros (...) que criticáramos también, y entonces nosotros criticábamos y Álamo se ponía a leer el periódico.

El método era idóneo para que nadie fuera amigo de nadie o para que las amistades se cimentaran en la enfermedad y el rencor. (14; énfasis nuestro)

Esta rutina de tedio y resentimiento se ve interrumpida por la repentina llegada de Lima y Belano, acontecimiento que será registrado el día 3 de noviembre, y que corresponde a la segunda entrada del diario: «lo que sucedió a continuación fue atropellado pero dotado de algo que a riesgo de ser cursi me atrevería a llamar maravilloso» (16; énfasis nuestro). En esta ocasión, los visitantes al taller son descritos en actitud impecablemente vanguardista: «La visita parecía de naturaleza claramente beligerante, aunque no exenta de un matiz propagandístico y proselitista». Y su presencia tiene desde las primeras líneas la clara función de alterar, de desestabilizar el aletargamiento enconado de las sesiones detonando «lo maravilloso a riesgo de parecer cursi»; es decir, el falseamiento de la experiencia poética que parece prolongarse en los espacios monótonos y algo tristes regimentados por Álamo:

La tensión, la corriente alterna de la tragedia se mascaba en el aire sin que nadie acertara a explicar a qué era debido. (...) Pero la poesía (la verdadera poesía) es así: se deja presentir, se anuncia en el aire, como los terremotos que según dicen presienten algunos animales aptos para tal propósito. (15-16; énfasis nuestro) 
García Madero se siente interpelado por estas presencias como un animal al borde de un cataclismo que es capaz de prefigurar en su propio cuerpo. «Entonces empezó la batalla»: batalla iniciática, podríamos decir, y que sella el destino del personaje, su destino de poeta. Al cabo de un breve momento en el que el taller parece transcurrir habitualmente, los realvisceralistas ponen en cuestión el método impartido por Julio César Álamo, y con eso dan pie a un altercado verbal bullicioso y confuso en el que se cruzan descalificaciones varias en su mayoría dirigidas a García Madero, Belano y Lima: «surrealistas de pacotilla», «falsos marxistas», «pedantes». La fraternidad que empieza a establecerse entre García Madero y los realvisceralistas, que toman partido por este (último agraviado por las críticas del hasta entonces maestro), queda definitivamente establecida cuando, en lugar de desembocar en unos predecibles y deseados golpes ("tengo que reconocer que me hubiese encantado», afirma García Madero), la reyerta es iluminada por la acción inesperada de Lima. Ulises es alentado a una especie de duelo poético por Álamo, y entonces: «Éste no se hizo de rogar y sacó de un bolsillo de la chamarra unos papeles sucios y arrugados (...) Y finalmente oí su voz que leía el mejor poema que yo jamás había escuchado» (17; énfasis nuestro).

Así, de estos papeles sucios y arrugados en el fondo del bolsillo de una chaqueta, probablemente también muy sucia y arrugada, brota ese poema «maravilloso» que rapta definitivamente a García Madero para las filas del realvisceralismo. La escena continúa con nuestros personajes adentrándose en un bar de la calle Bucareli, «en donde estuvimos hasta muy tarde hablando de poesía» (18) junto a otros miembros de la pandilla («no dijeron "grupo" o "movimiento", dijeron pandilla y eso me gustó» —-18-) y se le explica al postulante el origen especular del realvisceralismo, recuperado, como un residuo, de alguna escisión del Estridentismo mexicano, grupo de vanguardia artística realmente existente en los años 20 del pasado siglo, y replicado en el presente de la anécdota, a mediados de los años setenta del pasado siglo. Aparece el nombre de Cesárea Tinajero, el grupo canta rancheras, García Madero vomita después de componer la imagen poética que ratificará su pertenencia a la manada, Belano y Lima lo reconocen como uno de los suyos y le aseguran que «juntos cambiarán la poesía latinoamericana». A la mañana siguiente, el diarista no asiste a la Universidad. En su lugar, pasa todo el día en su cuarto, encerrado, «escribiendo poemas». Dos días después del enfrentamiento en el taller de Álamo, sentado en la Encrucijada Veracruzana, que pasará a ser uno de los escenarios más importantes de la trama, e interpelado por la camarera que unas páginas después convertirá en su amante, reconocerá con orgullo: «Sí, señorita, soy poeta». Es difícil pensar en una ceremonia de iniciación más lograda.

Los primeros poemas de García Madero que se dan a conocer al lector son escritos al día siguiente, en confesa imitación del poema escuchado de la boca de Ulises Lima, aquel «mejor poema que jamás haya escuchado». El joven regresa al mismo bar de la calle Bucareli, donde come, bebe y escribe a la expectativa de un nuevo encuentro con el grupo: «Había bebido demasiado, (...) llevaba muchas horas sin comer, y el alcohol y el hambre me estaban desconectando de la realidad (...) precisamente una de las premisas para escribir poesía preconizadas por el realismo visceral». Luego de cuatro cervezas e igual número de tequilas, García Madero cuenta con un pequeño repertorio de lo que podríamos considerar sus primeros textos realvisceralistas:

el primero sobre los sopes que sabían a ataúd, el segundo sobre la universidad: la veía destruida, el tercero sobre la universidad: yo corría desnudo en medio de una multitud de zombis, el cuarto sobre la luna 
del DF, el quinto sobre un cantante muerto, el sexto sobre una sociedad secreta que vivía bajo las cloacas de Chapultepec, y el séptimo sobre un libro perdido y sobre la amistad. (19)

Vemos pues cómo si bien los textos no aparecen copiados, sí son descritos, y no creo conveniente imaginar que dichas descripciones sean arbitrarias. Al contrario, podríamos pensar, más bien, que en la descripción de estos primeros siete poemas realvisceralistas de García Madero aparece esbozado el registro temático de esa poesía, o al menos podemos deducir lo que interesa a esa poesía: lo que busca capturar, o lo que la captura y en dónde se despliega. Podríamos imaginar que se trata pues del resumen descriptivo de un programa escritural. Podemos imaginar que se trata del resto onírico de un programa de escritura. $O$ del recuerdo muy vago de los poemas que se escribieron. E incluso, aunque esta operación es más arriesgada, podríamos pensar en la forma como esta descripción podría perfectamente delimitar el espacio poético en el que transcurre la escritura poética del propio Bolaño. Estos trasvases ambiguos son propiciados por este autor de manera constante, como vimos en la introducción, y como lo expresa la aseveración del también chileno Alejandro Zambra, «los poemas que escribe Bolaño son los poemas que escriben los personajes de Bolaño» (110), en una frase que retomaremos más adelante, cuando nos dediquemos a indagar con más profundidad en las consecuencias de esta relación establecida por Bolaño entre su poesía y su prosa.

Volviendo a la breve reseña que nos es proporcionada por García Madero, resulta llamativo que la primera de sus creaciones tenga como motivo el plato de comida de cruda materialidad orgánica ("casi descompuestos») que le sirven en la Encrucijada Veracruzana. Por lo prosaico y por su cercanía con cierto asco dadaísta, este poema descrito hará resonar los campos semánticos en los que se asienta la poesía realvisceralista en términos temáticos (lo que ella cuenta), al tiempo que apunta hacia algunos de los registros de la experiencia que ella parece convocar (de donde ella viene): el resto, la basura, lo sucio (como la chaqueta de Ulises Lima), algunas emanaciones corporales que impregnan la totalidad de Los detectives salvajes (el llanto, el vómito, el semen, la sangre), pero muy especialmente el tránsito de García Madero por estas primeras doscientas páginas. La escritura poética queda de entrada imbricada a un aspecto residual de carácter corporal, casi siempre impregnado de un fuertísimo componente sexual e incluso de cierta violencia, y esta será una condición que se replicará en muchos niveles de la escritura de Bolaño y de Los detectives... Es así, por ejemplo, como encontramos que la segunda tanda de textos del joven escritor tendrá la intención precisa de conseguir el acercamiento a quien se convertirá en una de sus amantes, la camarera Rosario, intento sumamente exitoso por lo demás. Durante el breve y afanado tránsito por el cuarto que ambos luego compartirán, la escritura alternará con un frenesí acompasado a sus actividades sexuales (en pleno idilio declara: «escribo como una locomotora» -118-), y los resultados de ambas actividades serán versificados en uno de los dos únicos poemas cuyo título conoceremos, «15/3», en referencia a la cantidad de orgasmos obtenidos por cada uno de estos personajes, en uno de sus agotadores encuentros. Lo sucio también encontrará lugar en el vocabulario empleado en estos poemas, que a juicio de Crispín Zamora, usan demasiadas «palabras malsonantes (...) Blasfemias, groserías, tacos, insultos» (126), ${ }^{4}$ como si Crispín estuviera describiendo no solo los poemas de García Madero sino también la cadencia verbal, vulgar y mexicana hasta la exasperación y lo cómico, del personaje de Bárbara Patterson, la gringa «lépera» (215), injuriando sin cesar a su pareja Rafael Barrios en un mexicano 
esperpéntico. El material gráfico no verbal que circula por la novela y que producen los realvisceralistas o sus allegados también acusa esta desmesura, esta vulgaridad: el cuadro que pinta María Font durante las primeras visitas de García Madero a su casa («era horroroso» — 45一), o las fotografías semipornográficas en las que se exhibe el propio Ernesto San Epifanio junto al adolescente hijo del embajador de Honduras, o las propuestas de diseño de Quim Font, diagramador de Lee Harvey Oswald, el órgano de difusión de los realvisceralistas:

El espacio que me señaló estaba lleno de rayas, rayas que imitaban la escritura, pero también de dibujitos, como cuando en los cómics alguien blasfema: serpientes, bombas, cuchillos, calaveras, tibias cruzadas, pequeñas explosiones atómicas. Por lo demás, cada página era un compendio de ideas desmesuradas que Quim Font poseía sobre el diseño gráfico. (96-97)

Por otra parte, la visión espectral de una universidad ruinosa y exánime, habitada por seres muertos en vida, y que contrasta con la verdadera vida y escritura poética es, por ejemplo, muy importante en la propia poesía de Bolaño, e incluso en la de Mario Santiago. Ambos la mencionan en sus poemas e incluso Bolaño colocará, como es sabido, el título Fragmentos de la universidad desconocida a uno de sus poemarios de los años noventa. ${ }^{5}$ En el personaje de García Madero, esta Universidad es, como ya vimos, la vida que abandona desde la primera página: su vida de abogado, pero también algunos círculos literarios, como los talleres que se dictan en la Facultad de Filosofía y Letras, y que se contraponen claramente a su vida de poeta (realvisceralista) que huye de este escenario, «corriendo» y «desnudo», al decir de (la descripción) del poema. De hecho, no volverá a la Universidad hasta el día 24 de noviembre, en el que anotará haberse quedado detenido ante sus puertas, sin que se sepa si se refiere a la Facultad de Derecho o a aquella donde se dicta el taller de Álamo. Para el caso, pareciera que vienen a ser lo mismo, en la medida en que representan cierto modo de la institucionalidad literaria de la cual el poeta debe escapar para poder mantenerse con vida, es decir, genuinamente poeta. Y también será la «universidad» descartada por un Belano adolescente que decide dejar la escuela para entregarse a su vocación de escritor, tal como es narrada por Perla Avilés páginas más adelante (171-175), mientras recuerda la adolescencia tempranísima de Belano en uno de los primeros episodios de ese largo y diverso interrogatorio que constituye el segundo tramo de Los detectives...

Tanto los temas de «el cantante muerto» como el de aquella «sociedad secreta que vivía bajo las cloacas» del principal parque urbano del DF podrían verse replicados en el último poema, que habla de «un libro perdido y sobre la amistad». Así, las filiaciones literarias, pero también las carnalidades de la camaradería poética ligadas a un mundo subterráneo (infrarreal) y en algunos sentidos sucio, son formas de la fidelidad que toman una importancia central, obvia, en el devenir de los acontecimientos de Los detectives salvajes, y que será un aspecto que examinaremos con más detenimiento en el próximo apartado.

La amalgama de violencia, sexo, sordidez y fecundidad originaria se observa de forma nítida nuevamente en la anécdota que Ulises Lima refiere a los personajes de Alberto Moore, Julita Moore y Luis Sebastián Rosado en las brumas del significativo Priapo's, antro nocturno al que son conducidos junto a Lima y otros dos realvisceralistas en una escena que posee todos los componentes que hasta ahora hemos mencionado. El escenario sórdido y neblinoso, «descabelladamente vulgar» (184), resuena con el aspecto de la Encrucijada Veracruzana, que es descrita una 
y otra vez como «cochambrosa», «atroz huronera o cuchitril» (233), y frecuentada por asistentes de aspecto «patibulario». Tal es la visión de Juan Sebastián Rosado del local al que acuden:

escenas dislocadas en donde jóvenes maleantes sombríos danzaban con jóvenes sirvientas desesperadas o con jóvenes putas desesperadas en un torbellino de contrastes que, lo confieso, acentuó si eso es posible mi borrachera. Después hubo una pelea en alguna parte. No vi nada, sólo oí gritos. Un par de matones emergieron de las sombras arrastrando a un tipo con la cara ensangrentada (...) después me recuerdo a mí mismo bailando un bolero con Piel Divina (...) recuerdo haberle susurrado a mi pareja (de baile) que nuestra actitud seguramente iba a enardecer a los demás bailarines y espectadores. (...) Alguien me insultó. (187-188)

En medio de este ambiente Lima recita el poema de Rimbaud «Le coeur volé», para luego pasar a exponer una difusa parábola que parece tener la función de jalonar y anclar los orígenes de la poesía moderna hasta la Santa Teresa sonorense en la que culminará, precisamente, el destino de Los detectives salvajes. Así, según Lima, el objeto al que Rimbaud dedicará dicho poema (el caporal de mon coeur) había sido un recluta veterano de la invasión francesa a México (1862) en la que había sido violado y torturado por los habitantes de la ciudad de Villaviciosa (ciudad en la que será encontrada finalmente Cesárea Tinajero), logrando escapar poco después. Luego ese mismo recluta, de regreso en Francia, violaría a su vez al joven poeta que se encontraba en su ruta de Charleville a París, para unirse a las filas de la Comuna (1871). Nuevamente, vida y ficción se entreveran y se iluminan mutuamente: el hecho de que la revista que Bruno Montané (el Felipe Müller de Los detectives...) y el mismo Bolaño publicaran en Barcelona en el año 1983 se llamara «Rimbaud vuelve a casa», parece estar espectralmente relacionado con esta anécdota curiosa referida por Lima, y quizás por el propio Mario Santiago. Fabulada o real, en todo caso, el relato de Lima en el Priapo's apunta hacia un recorrido en el que la violencia y el sexo determinan el nacimiento de cierto tipo obra poética, de la cual los realvisceralistas se quieren herederos privilegiados, en su calidad de poetas mexicanos, y vanguardistas, «discípulos de Marinetti y Tzara», al decir de Juan Sebastián Rosado.

Otro aspecto lateral pero llamativo a tomar en cuenta es la forma en que algunos nombres clave parecen apuntar, también, hacia este magma oscuro en el que deseo, erotismo, muerte y asco se imbrican para dar lugar al hecho estético tal como es postulado por el grupo realvisceralista. Así, desde su mera nominación personajes como Amadeo Salvatierra, el relator de los días de fundación del primer realvisceralismo, Encarnación Guzmán, la causante de la escisión entre Estridentismo y realvisceralismo y por supuesto sobre todo la propia Cesárea Tinajero, musa y tótem, partera y vasija del segundo realvisceralismo, o Auxilio Lacouture, «madre de la poesía joven mexicana» $\mathrm{y}$ «versión femenina del Quijote», lucen como señalamientos fundacionales acerca del germen violento y carnal en el que la poesía acontece. Mención aparte amerita el ya aludido Piel Divina, participante de importancia en la escena recién descrita. Curiosamente, Piel Divina es el único personaje realvisceralista que coincide nominalmente con su tándem infrarrealista («ese nombre tan sugerente, tan acertado» -207-), de forma que varios autores mencionan su actual y real existencia como artista plástico que vive en París. ${ }^{6}$ Pareciera que Bolaño decidiera enfatizar la función de este apelativo de resonancias corpóreas, sensoriales, conservando para él su «verdadero» seudónimo, e imprimiendo en el texto toda su erótica extravagante, expansiva, proletaria o 
a todas luces lumpen, ilimitada y en cierta medida criminal (el personaje morirá violentamente, vinculado de forma confusa al tráfico de drogas): en muchos sentido un infrarrealista ejemplar.

le pregunté otra vez cómo se llamaba y él dijo Piel Divina con tanta naturalidad y seguridad (mucha más de la que yo hubiera empleado para decir Juan García Madero) que por un momento llegué a creer que en los meandros y pantanos de nuestra República Mexicana existía de veras una tal familia Divina. (83)

Quizás sea relevante a estas alturas relacionar los temas presentes en la poesía de Los detectives... con algunos textos de Mario Santiago Paspaquiaro, publicados en la antología de poesía latinoamericana que comentamos unos párrafos atrás, y que Roberto Bolaño preparara en 1979 para editorial Extemporáneos, en Ciudad de México: Muchachos desnudos bajo el arcoíris de fuego. Por ejemplo, el ya algo célebre «Consejos de un discípulo de Marx a un fanático de Heidegger» será declinado de forma evidente años más tarde por Bolaño en la novela que firmará en forma conjunta con Antoni García Porta, titulada Consejos de un discípulo de Morrison a un fanático de Joyce (1984), obra que constituirá la primera publicación en prosa del autor chileno, dicho sea de paso. Por otra parte, «En cualquier momento acontece un poema», segunda pieza de Santiago en la antología, esboza un ars poética en total concordancia con los imperativos programáticos que declaran una y otra vez las posibilidades de la tecnología poética como forma radical del despertar, y también en sintonía con los temas realvisceralistas que hasta ahora hemos mostrado:

que la vida siga siendo tu Taller de Poesía

\& ojalá \& electrifiques la energía de tu tormenta interior

junto a la muchacha con agilidad de velero

que has elegido como la compañera

de tus próximos brincos

que el Amor o la demencia que más se le aproxime

te habite $\&$ te aligere los talones

\& te lustre el brillo de los ojos. (174)

En ese mismo texto en el que se declara el advenimiento de la experiencia poética «en cualquier momento", la correspondencia entre poema y cotidianidad es por supuesto central, y será sobre este núcleo cuya naturaleza oscila entre lo milagroso y el desecho donde parece ejercitarse la poesía infrarrealista, y quizás también la poesía de los personajes de Los detectives...

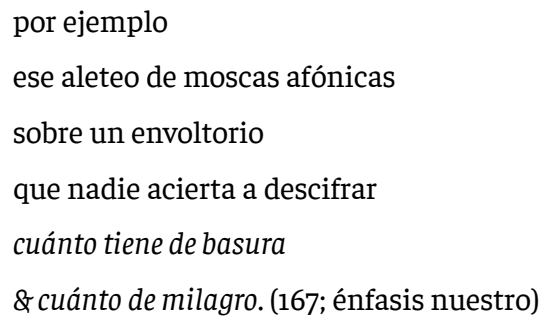

Antes de pasar a otro aspecto de la poesía realvisceralista, como lo son los efectos y acciones que la poesía desencadena en los personajes (aparte de la adhesión inaugural ya mencionada), 
añadamos un comentario a propósito de la figura de Mario Santiago y de su contraparte ficcional Ulises Lima. La presencia de Santiago/Lima acá resulta iluminadora en varios sentidos, al irradiar con permanente intensidad su influencia al universo bolañiano. Su figura ha resultado fundamental en la construcción de la mitología del escritor Bolaño, quien calca en Ulises Lima el retrato de su amigo, pero además aquel no deja de recordarlo y mencionarlo en las entrevistas que dará luego de la publicación de Los detectives..., calificándolo una y otra vez como «el mejor poeta que haya conocido». Así, tenemos que en primer lugar Ulises Lima constituye una figura central en la pesquisa múltiple que trama la novela, al ser uno de los dos caudillos principales del realvisceralismo cuyo paradero, destino y silueta se intentarán delinear. Pero también es interesante observar el lugar que ocupa en el autorretrato que Bolaño como poeta teatraliza en ocasiones fuera del texto estrictamente ficcional. Es acá donde nuevamente la figura de Mario Santiago destella al constituirse como el poeta puro, o el poeta en estado puro, rechazando no solo la publicación sino incluso el ejercicio de la prosa misma, como una forma de no condescender a la disminución de la radicalidad de su apuesta artística. La figura de Mario Santiago, más salvaje y aún más indomesticada que la de Bolaño, encarnando en sí mismo al poeta como resto, como residuo inasimilable, constituye su reverso al permanecer realmente por fuera de toda esa institucionalidad literaria a la que Bolaño efectivamente se integrará de forma más o menos problemática (sobre todo en el contexto nacional chileno) a partir de la publicación de $L a$ literatura nazi. En este sentido, el silencio de Santiago Paspaquiaro de cara al campo literario, que no lo reconoce como escritor válido sino luego de la «irradiación» realvisceralista sobre él, parece tener cierta correspondencia con el silencio que hacen los poemas de los realvisceralistas en Los detectives salvajes. Mario Santiago como inspiración directa de Ulises Lima, será el verdadero "gaucho insufrible». Inasible, inadmisible, inasimilable: el poeta como resto. Derrotado, como la verdadera poesía, pero vivo, lleno de amor:

En el camino de los perros mi alma encontró

a mi corazón. Destrozado, pero vivo,

sucio, mal vestido, y lleno de amor.

En el camino de los perros, allí donde no quiere ir nadie. (32)

\title{
Acciones y afectos: los verbos realvisceralistas
}

\author{
Un cuerpo se alfabetiza junto a otro cuerpo \\ \& así se funda la Universidad de la Ternura \\ Mario Santiago
}

De forma rotunda, avasallante, la palabra poética esgrimida por los realvisceralistas, o por aquellos poetas que admiran y leen, desencadena los efectos de un compromiso corporal en el que la carne es convocada más allá de su propia voluntad, y en el que los cuerpos parecen desbordarse por la experiencia de la poesía. Esta invocación con resultados automáticos, incluso casi de automatismo, parece aludir a algo del embrujo esencial de la palabra poética, a su carácter mágico, prometeico, fundante: «a la manera de ensalmos y sortilegios el poeta despierta las fuerzas secretas del idioma» (Paz:56). 
De la literatura realvisceralista y de las lecturas que acompaña a la pandilla conoceremos, pues, la sustancia de la que está hecha, como vimos en el apartado anterior, pero también los efectos que ella es capaz de animar. Los antecedentes de esta suerte de performatividad dionisíaca de la palabra poética, y literaria, en general, se observan ya en el grupo de vanguardia de los Estridentistas, de cuyo protagonista el personaje de Amadeo Salvatierra afirma lo siguiente:

Pico de oro era Manuel (Maples Arce). ¡Pico de oro! (...) Les dije: muchachos, así era la prosa de Manuel Maples Arce, incendiaria y atrabancada, llena de palabras que nos ponían cachondos, una prosa que puede que ahora no les diga nada pero que en su época cautivó a generales de la Revolución, a hombres bragados que habían visto morir y que habían matado y que cuando leyeron o escucharon las palabras de Manuel se quedaron como estatuas de sal o estatuas de piedra, como diciendo qué chingados es esto, una prosa que prometía una poesía que iba a ser como el mar, como el mar en el cielo de México. (262; énfasis nuestro)

La textura de la escritura de Los detectives salvajes testimonia esta primacía del cuerpo afectado: es así como en ella es perceptible el predominio de cierto materialismo a través de la presencia permanente de cuerpos en movimiento y, en ellos, de la alternancia, tal como ocurre en la prosa con aspiraciones poéticas de Maples Arce según el fragmento recién citado, de lujuria, perplejidad y abismo. El ritmo narrativo de la novela, incluso en los momentos de mayor alcance descriptivo (las pocas catálisis presentes en él) no parece poder evitar volcarse vertiginosamente hacia la acción o, más aún, a un innegable dinamismo de tintes apocalípticos: así, la corta descripción de un paisaje relata «un cielo gris, pero brillante como si hubiera ocurrido ataque nuclear» (83); o también: «afuera la gente camina aprisa, encogida, no como si aguardara una tormenta, sino como si la tormenta ya estuviera aquí» (123; énfasis nuestro en ambos casos). El mismísimo ejercicio de pensar transluce, en estos personajes, esa paradójica vitalidad dantesca, de forma que García Madero reflexiona en casa de las Font: «Comí sentado en la cocina, pensando en el futuro. Vi tornados, huracanes, maremotos, incendios» (74); y más adelante, María Font se dice a sí misma que "todo se fue enredando dentro de mi cabeza, como si las palabras que yo tenía para decirles fueran plantas y éstas de pronto comenzaran a secarse, a perder color y fuerza, a morirse» (226; énfasis nuestro).

Además de corresponder a la permanente sorpresa de García Madero frente a los acontecimientos que vive, es decir, de dar forma al empuje reconstructivo y memorioso de la novela, la exacerbación de la peripecia se sostiene en muchos momentos al presentificar el cuerpo afectado por la poesía, y es por lo tanto un efecto de la naturaleza de lo narrado: se pone en escena (se lee) cómo lo leído por los personajes despierta, una y otra vez, en el contacto con los otros, en el contagio de viviente a viviente, de cuerpo a cuerpo, y cómo se traduce en una movilidad acelerada que acompaña esta intensificación de la experiencia a partir de la contaminación que produce la poesía. Así, los personajes que habitan las páginas de Los detectives salvajes reaccionan y chocan, se oponen, se encuentran y se calibran mutuamente en la experiencia literaria, haciendo de la superficie del libro y de la poesía el espacio de un drástico encuentro corporal.

Será pues inmerso en esta voluptuosidad, exasperada pero extrañamente edificante (y siempre intensamente literaria), anclada en la presencia de lo sórdido y de lo residual, que transcurre la educación sentimental de García Madero y el posterior retrato a contraluz de Belano y Lima, junto a sus compañeros, histéricos e hiperestésicos: todos ellos vivirán o padecerán la poesía como una esgrima que punza la carne y la hace reaccionar, apasionarse, convulsionarse, 
exasperarse; suscitando, en ese México pretérito de 1975, y también en buena medida en los años en los que se desarrolla la pesquisa de las páginas posteriores, su vivificación.

El valor de una palabra dominada por el pathos o la importancia de un decir con la capacidad de afectar se introduce desde las primeras páginas de Los detectives... Recordemos el germen de aquella batalla iniciática en la que García Madero se enfrenta a Álamo: las asperezas tienen su inicio, precisamente, en la puesta a prueba del saber retórico del presunto mentor.

Por otra parte no podría decir que Álamo fuera un buen crítico, aunque siempre hablaba de la crítica. Ahora creo que hablaba por hablar. Sabía lo que era una perífrasis, no muy bien, pero lo sabía. No sabía, sin embargo, lo que era una pentapodia (que, como todo el mundo sabe, en la métrica clásica es un sistema de cinco pies), tampoco sabía lo que era un nicárqueo (que es un verso parecido al falecio), ni lo que era un tetrástico (que es una estrofa de cuatro versos). ¿Que cómo sé que no lo sabía? Porque cometí el error, el primer día de taller, de preguntárselo. No sé en qué estaría pensando. El único poeta que sabe de memoria estas cosas es Octavio Paz (...). Pero yo no me arredré y después de que me destrozara un par de poemas en la segunda sesión a la que asistía, le pregunté si sabía lo que era un rispetto. Álamo pensó que yo le exigía respeto para mis poesías (...).

—No me vengas con chingaderas, García Madero — dijo Álamo.

-Un rispetto, querido maestro, es un tipo de poesía lírica, amorosa para ser más exactos, semejante al strambotto, que tiene seis u ocho endecasílabos, los cuatro primeros con forma de serventesio y los siguientes construidos en pareados. (14-15)

intenté explicar una vez más lo que era un rispetto; Álamo estaba rojo de rabia; los miembros del taller me acusaron de pedante (uno dijo que yo era un academicista); los realvisceralistas me defendieron; ya lanzado, le pregunté a Álamo y al taller en general si por lo menos se acordaban de lo que era un nicárqueo o un tetrástico. Y nadie supo responderme. (17)

El desbordado catálogo de elementos de métrica y oratoria clásica que García Madero exhibe provocan la antipatía de sus colegas talleristas y la irritación de Álamo, a la vez que desata la hilaridad del lector, que no puede permanecer indiferente ante el anacronismo ampuloso y hasta cierto punto bastante extravagante de tal repertorio. ${ }^{7}$ En este sentido, nos resulta llamativo el hecho de que el humor fuera un rasgo resaltado por el jurado que premió Los detectives salvajes en Caracas (Manzoni:206), lo cual deja constancia de la rotundidad con que la risa, como efecto del cuerpo, ha sido experimentada por quienes se acercan a la novela. Sin embargo, más allá de proporcionar un innegable elemento cómico al relato, proponemos que este saber sobre el quehacer poético que García Madero detenta, bordeando el ridículo y sacando de quicio a más de uno («a ver, sabelotodo», le dice Lupe -687-), es un índice esencial tanto de su identidad de escritor, es decir, de su inadvertida o anticipada pertenencia a la manada, como de las distintas ponderaciones y filiaciones que la verdadera poesía amerita para Roberto Bolaño. ${ }^{8}$ Ya que, a fin de cuentas, ¿qué es la retórica, sino la inclinación de los afectos por medio de la palabra, la suscitación de las pasiones mediante el conocimiento de las formas del lenguaje, y la constatación de que el verbo, más allá de sus usos racionales, o precisamente a causa de ellos, tiene efectos no del todo controlables por quien la escucha y la recibe? Es precisamente frente a la imposibilidad del pretendido maestro de persuadir o de conmover por su decir (ese tedio que inunda el taller de Álamo, su 
«hablar por hablar»), como García Madero se dirige a los realvisceralistas, construyendo Bolaño con esto una oposición nítida entre la literatura realvisceralista, y el lugar igualmente exasperado de una literatura otra, cadavérica o a todas luces canalla, que no dejará de aparecer, ni en Los detectives salvajes, ni en otras narraciones o intervenciones «no ficcionales» de Bolaño.

La vinculación entre pasiones, palabra y cuerpo se encuentra ya en Aristóteles. Así, en el segundo libro de la Ética a Nicómaco el filósofo ofrece una definición de la pasión como todo aquello que vaya acompañado de placer o dolor, recalcando lo material de la pasión, su pertenencia tanto al cuerpo como al alma, en contradicción con posiciones que se inclinan por una concepción más espiritualista de las mismas, como las exhibidas por Platón en el Filebo (Conde Soto:121). Es también en la Ética donde el estagirita insiste en la capacidad de afectar al cuerpo en función de las pasiones: «Finalmente, por lo que respecta a las pasiones, se dice que nos mueven, pero en cuanto a las virtudes y vicios se dice no que nos mueven, sino que nos disponen de cierta manera» (Aristóteles:1106a; énfasis nuestro). La caracterización de esta articulación entre discurso y pasión en Aristóteles se prolonga en De Ánima, cuando el estagirita constata que las pasiones afectan y son intrínsecas a la materia, es decir, al cuerpo.

Los fundamentos de la textura narrativa de Los detectives... se encuentran allí: en la vehemencia suscitada por una palabra in-corporada, que entra al cuerpo como una enfermedad o como un virus, por esa inclinación de la carne a reaccionar a la poesía más allá de su voluntad, y es en este sentido que su lógica será la de las contingencias de ese afecto que la palabra poética vehiculiza. Este cuerpo entusiasmado (o enfermo) de poesía, arrastrado por sus innegables y orgánicos efectos perlocutivos, se hará visible en las primeras lecturas de García Madero: así, el libro de Pierre Louÿs que compra y lee el 6 de noviembre, Afrodita, ${ }^{9}$ apenas tres días después de abandonar la facultad («me produjo una erección de caballo» - 22-), o el poema de Efrén Rebolledo, «El Vampiro», que recita mientras se masturba febrilmente «una, dos, tres, hasta diez o quince veces» (24). El texto de Rebolledo, modernista mexicano, se encuentra en su poemario Caro victrix: «el triunfo de la carne», o «el triunfo de los apetitos», lema quizás extrapolable al conjunto de la literatura realvisceralista como tal, o a sus ambiciones.

La multiplicación de los verbos a lo largo del relato da fe de aquella aspiración de Bolaño de hacer de Los detectives... «una narración en la estela del Huckleberry Finn» de Mark Twain (Bolaño, 2013:327), es decir, una novela de aventuras; y denotan esta pérdida de control sobre un cuerpo dominado por la poesía, tomado por la vehemencia de la poesía: pelear, caminar, fumar, dormir, comer, coger, reír, vomitar, sonrojarse, desmayarse, afiebrarse, llorar... todos ellos verbos que determinan el carácter de la peripecia, al reincidir en apuntar al carácter orgánico del afecto efectuado por la literatura. Algo de la desmesura que caracteriza a «esos poemas larguísimos» (Bolaño, 2017:181) también se encuentra, pues, presente en estos cuerpos fuera de control y de quicio. Testimonio de esta mortificación rendirá el segundo poema de título conocido, «Todos sufren», al señalar inequívocamente, en su sencillez casi ridícula, el intenso pathos vehiculizado por la poesía de nuestra pandilla: poemas patéticos, poemas patológicos, como aquellos, «rabiosos» (y despechados) que Ulises Lima le escribe a Claudia Lanzmann y le lee impúdicamente, exhibiendo lo que Norman Bolzman considera «su dolor, su obstinación de mula, su profunda estupidez».

Uno de los efectos más notorios de esta contaminación ejercida por la poesía es, como hemos visto, el desperdigamiento de un afecto que aglomera a la manada, para decirlo —ahora — en términos deleuzianos: «Pues el afecto no es una experiencia personal, tampoco es un carácter, es la efectuación 
de una potencia de manada, que desencadena y hace vacilar el yo» (Deleuze y Guattari:245). Es así como presenciamos la última adhesión al realvisceralismo (ese otro último salvaje que será García Madero), y es esta incorporación postrera la que desencadena los acontecimientos y el despliegue inicial de la trama, ${ }^{10}$ efectuando ese afecto con una vehemencia tal que, al término de la narración, nos será difícil reconocer al personaje que se nos da a conocer en las primeras páginas de la novela."

Esta preeminencia de cierta pulsión afectiva que aglutina a la pandilla en Bolaño puede leerse, en la estela de Deleuze y Guattari, a partir de los estudios acerca del afecto que han cobrado cierta relevancia en el campo de la crítica literaria y cultural. Es a partir de la descolocación de las coordenadas de lectura e interpretación de los fenómenos colectivos, así como de las teorías que pretendían ordenar su cambio que siguió al fin de la Guerra Fría, que se ha insistido en tomar en cuenta «el factor del afecto como un nivel ineludible para el estudio de las formas con frecuencia inorgánicas y discontinuas a partir de las cuales se manifiesta y expresa lo social» (Moraña:314), realzando y reevaluando en ellos el papel de lo nomádico, lo doméstico y la intimidad. Todos estos aspectos son considerados puntos de fuga relevantes al momento de interpretar campos tradicionalmente entendidos como políticos, públicos y estables. En este sentido el afecto, tal como lo entiende Deleuze, nos sirve para entender la agrupación de los realvisceralistas, ya que no cabe duda de que se trata de una manada que se ordena y reúne en torno a este factor. Es así como García Madero constata, entusiasmado, durante sus primeros encuentros realvisceralistas, en casa de Ulises Lima: «Nadie ha leído ningún poema mío y sin embargo todos me tratan como a un realvisceralista más. ¡La camaradería es espontánea y magnífica!» (34). No hace falta conocer los poemas para que el efecto performativo de la poesía haga lo suyo. En este caso, la palabra, aun en su condición de no pronunciada, funciona como garantía, de la misma manera que los realvisceralistas se asumen discípulos de Cesárea Tinajero sin necesitar conocer su obra, o más aún, precisamente porque no la conocen: «No hemos leído nada de ella, dijeron, en ninguna parte, y eso nos atrajo» (194), sentencian Belano y Lima según el relato de Amadeo Salvatierra. El mismo procedimiento parece sostener la fidelidad indeclinable de Cesárea por su amiga Encarnación Guzmán, fidelidad por cuya causa la poeta se separa del grupo de los Estridentistas y funda su propio movimiento, cuando Manuel Maples Arce manda a callarla y Cesárea decide, en consecuencia, no acompañar más al grupo de vanguardia en sus reuniones:

Y Encarnación puede que no fuera una buena poeta (como yo mismo [dice Amadeo]), puede que incluso ni siquiera fuera poeta, buena o mala (como yo mismo, ay), pero sí que fue buena amiga de Cesárea. ¡Y Cesárea era capaz de quitarse el pan o la tortilla de la boca por sus amigos! (331)

La lealtad profesada al movimiento y sobre todo a los colegas realvisceralistas se prolongará más allá de la disolución del grupo, justificando insistentes cierres de filas ante la exclusión tajante de Arturo pero sobre todo de Ulises, de las antologías que se publican en México después de su partida a Europa, cuyo editor «no quiere tratos de ninguna especie con los realvisceralistas», a lo que Jacinto Requena responde: «yo soy realvisceralista (...) y si ese cabrón no mete a Ulises, pues que tampoco cuente conmigo» (335). Juan Sebastián Rosado, contagiado por el afecto realvisceralista, también se dirige a Zarco buscando colocar los únicos dos poemas que ha leído de su amante, Piel Divina, quien declina la invitación (rechazada por el editor de la revista, dicho sea de paso) frente a la ausencia de otros realvisceralistas en la muestra: 
me preguntó si la antología de Ismael Humberto incluía a Pancho y a Moctezuma Rodríguez. No, dije, creo que no. ¿Y a Jacinto Requena y a Rafael Barrios? Tampoco, dije. ¿Y a María y a Angélica Font? Tampoco. ¿Y a Ernesto San Epifanio? Negué con la cabeza, aunque en realidad yo no sabía, ese nombre no me sonaba de nada. ¿Y a Ulises Lima? Miré fijamente sus ojos oscuros y dije que no. Entonces es mejor que yo tampoco aparezca, dijo él. (339-340)

En esta línea puede ser leída la muy citada e iconoclasta nomenclatura que esgrime Ernesto San Epifanio, y según la cual el canon poético hispanoamericano y por momentos el occidental en su totalidad puede ser clasificado según una sorprendente correlación entre géneros y sexualidad: la novela será heterosexual y la poesía homosexual, por ejemplo; mientras que el parnaso poético se dividirá en «maricones, maricas, mariquitas, locas, bujarrones, mariposas, ninfos y filenos» (100):

Las dos corrientes mayores, sin embargo, eran la de los maricones y la de los maricas. Walt Whitman, por ejemplo, era un poeta maricón. Pablo Neruda, un poeta marica. William Blake era maricón, sin asomo de duda, y Octavio Paz marica. Borges era fileno, es decir de improviso podría ser maricón y de improviso simplemente asexual. Rubén Darío era una loca, de hecho la reina y el paradigma de las locas.

—En nuestra lengua, claro está —aclaró—; en el mundo ancho y ajeno el paradigma sigue siendo Verlaine el generoso.

Una loca, según San Epifanio, estaba más cerca del manicomio florido y de las alucinaciones en carne viva mientras que los maricones y los maricas vagaban sincopadamente de la Ética a la estética y viceversa.

El panorama poético, después de todo, era básicamente la lucha (subterránea), el resultado de la pugna entre poetas maricones y poetas maricas por hacerse con la palabra.(101)

La profusión de listas (la larga lista de Ernesto San Epifanio, pero también la de los escritores por leer anotados por García Madero, o de los poemas escritos por él, o de sus coitos: «Hice el amor llevando la cuenta» -118-), o de los libros robados en las librerías del DF; la permanente contabilidad de los nombres, por así decirlo, acentúan el desinterés del contenido poético en términos de sentido (qué significa lo que se dice), y focalizan el interés en su irrupción dentro de la trama así como su incorporación en diversas cadenas de contagio en la que la palabra es, de nuevo, incorporada. Cómo circula lo que se dice, qué clase de acciones detona: «Durante el trayecto les leí los últimos poemas que he escrito, unos once o doce, y creo que les gustaron» (37; énfasis nuestro).

En este grupo de "magnífica camaradería» y también de "generosidad ilimitada» (91) — en virtud de la cual García Madero, que no vuelve a casa de sus tíos desde la primera entrada de su diario, recibe, durante los tres meses que dura la primera parte de su aventura, alojamiento, comida y hasta dinero por parte de la pandilla —, opera una agitada circulación de libros, de manera que «lo que lee un realvisceralista es leído acto seguido por todos los demás» (34), testimoniando así otras formas de contagio, igual de fundamentales que la devoción en apariencia sin límites profesada a una poeta no leída. Ernesto San Epifanio le aclara a García Madero en tono irónico:

Pero si en ese grupo sólo leen Ulises y su amiguito chileno. Los demás son una pandilla de analfabetos funcionales. Me parece que lo único que hacen en las librerías es robar libros (...) después se los regalan a Ulises y a Belano. Éstos los leen, se los cuentan y van por ahí presumiendo que han leído Queneau, por ejemplo, cuando la verdad es que se han limitado a robar un libro de Queneau, no a leerlo. (66; énfasis del autor) 
El robo vendría a ser una relación lateral, desviada, criminal como forma de acceso a la cultura, y esta relación se ve reforzada por la —en apariencia — principal forma de financiamiento de la primera revista realvisceralista, y de Arturo y Ulises en general: el menudeo de drogas. Por otra parte, el préstamo de libros y las recomendaciones de lectura juegan su papel y contribuyen a ceñir la red realvisceralista: a los múltiples repertorios que engrosarán la prosa de Los detectives..., habrá que sumar las permanentes anotaciones que García Madero apura, recogiendo presurosamente la caudalosa estela de libros que sus colegas cargan consigo, y que arrastran de un encuentro a otro como extensiones de su propia materialidad corporal («cargaban libros», etc.).

La heterogeneidad carente de un centro estable que caracterizaría a la manada se hace notoriamente palpable en la enumeración de las adscripciones políticas de algunos realvisceralistas, adscripciones que también parecen desafiar el orden normado de la distribución de los afectos políticos. Así, en la corta entrada en la que García Madero se dedica a listar las militancias políticas del grupo (el 20 de noviembre, —93-), se juntan troskistas, anarquistas, sindicalistas, feministas radicales (¿sadomasoquistas?), el fundador del Partido Comunista Homosexual de México y de la primera Comuna Proletaria Homosexual Mexicana, y, por supuesto, herederos de algún combatiente de la Batalla del Ebro (el abuelo de las Font). Esta multiplicidad —rizomática, podríamos decir con Deleuze, o en todo caso diversa hasta el desperdigamiento- de la pandilla realvisceralista se opone muy claramente, por ejemplo, a la más bien uniforme y algo sumisa delegación mexicana con la que Ulises parte a Nicaragua a principios de los ochenta (405-418), gracias a un desliz de Hugo Montero, uno de los organizadores, y frente a la cual desaparece sin dejar rastro. La delegación será liderada, dicho sea de paso, por el propio Julio César Álamo, arbóreo conductor de esa pequeña masa de poetas. Esta heterogeneidad origina una desconfianza sutilmente plasmada en la novela, cuando el testimonio del argentino Fabio Ernesto Logiacomo, presunto ganador del premio de poesía Casa de las Américas del año 1975, transluce su inquietud: «Yo era un experto en poetas jóvenes y allí ocurría algo raro, faltaba algo, la simpatía, la viril comunión en unos ideales, la franqueza que preside todo acercamiento entre poetas latinoamericanos» (181; énfasis nuestro). En oposición al aglutinamiento por los ideales, al compacto acuerdo homogeneizante que fundamentaría una política de masas, vemos cómo los realvisceralistas se juntan a partir de una retórica de los afectos o, también podríamos decir, por los inclasificables efectos afectivos de la palabra poética: «aquí ocurría algo raro». En continuidad con esta desconfianza, el poeta peruano Roberto Rosas, compañero de buhardilla de Ulises Lima durante sus día en París (la autodenominada "Comuna de Passy»), testimonia el desarreglo entre los márgenes que permiten comprender la política, o cierto tipo de política, y la articulación propuesta por los realvisceralistas, cierto desacompasamiento entre política y poética:

Recuerdo que a Ulises le agradaba la poesía joven francesa. Puedo dar fe. A nosotros, al Pueblo Joven Passy, la poesía joven francesa nos parecía un asco. Hijos de papá o drogadictos. Entiéndelo de una vez, Ulises, solía decirle, nosotros somos revolucionarios, nosotros hemos conocido las cárceles de Latinoamérica, ¿cómo podemos querer una poesía como la francesa, pues? Y el cabrón no decía nada, sólo se reía. (282)

Por último, la violencia de este cuerpo comprometido para la poesía que encontramos en Bolaño contrasta, por ejemplo, con otras experiencias literarias narradas, análogas en la intensidad, pero que apuntan hacia una relación más intelectiva, si se quiere, con la palabra y sus consecuencias. 
Así, este silencio alrededor de las reiteradas conversaciones sobre poesía podrían compararse, por ejemplo, con la también muy larga e intensa digresión que mantienen Tardewski y Renzi en la segunda parte de Respiración Artificial (2001a) llamada, precisamente, Descartes, y en la que se exponen algunas tesis que Ricardo Piglia declinará como crítico literario (y que en la novela se presentan «intensificadas por el efecto de la ficción», según su propio decir), como las hipótesis en torno a los dos linajes de Borges. Lo ocurrido en esa madrugada en ese pueblo perdido de Entre Ríos entre el sobrino de Marcelo Maggi y el emigrado polaco (esa maravillosa pasión de las ideas mientras se espera, el amor intelectual que también con un furor contagioso transmiten muchos de los personajes de Piglia, incluyendo al propio Piglia) contrasta, en muchos sentidos, con la intelectualización difusa o carnavalesca, es decir, abiertamente sexualizada y vulgar, inarmónica y disonante que transcurre en Los detectives salvajes.

Pero, sobre todo, esta poesía del compromiso corporal objetará la mediocritas aurea, esa preciosa y sosegada mediocridad, la somnolencia desvitalizada y prudente de la que hacen alarde los personajes que anticipan el cierre de la segunda parte de la novela, y que otorgan su testimonio en el capítulo 23 de la misma. Es frente a este justo medio que parece sepultar la experiencia de lo literario, que el destino de Belano, de Lima, y de los demás poetas realvisceralistas se planta, un destino marginal pero indudablemente anclado en aquello muy real, que es el cuerpo indomesticado y perturbador de la poesía y del poeta mismo.

\section{Notas}

1 «La batalla del Ebro» es también nombre de la librería que regenta el anciano español Crispín Zamora, y una de las tantas visitadas por García Madero en su persecución a Belano y Lima por las calles del DF. Con Zamora nuestro protagonista tendrá un par de encuentros significativos (Bolaño, 2017:126, 137-138). En Bajo el volcán, también durante esa misma jornada del 2 de noviembre, el Cónsul es asesinado por fascistas mexicanos.

2 Título de la antología de jóvenes poetas latinoamericanos preparada por Bolaño (1979). Frente a esta imagen podemos recobrar unos versos muy citados por la crítica bolañiana, provenientes del poema «Autorretrato a los veinte años»: «Y me fue imposible cerrar los ojos y no ver/ aquel espectáculo extraño, lento y extraño/ (...) miles de muchachos como yo, lampiños/ o barbudos, pero latinoamericanos todos/juntando sus mejillas con la muerte» (2010:14).

$3 \mathrm{Al}$ respecto, revisar https://www.pagina12.com.ar/ diario/suplementos/radar/subnotas/4753-799-2008-08-12. html y http://www2.latercera.com/noticia/ los-detectives-retratan-a-bolano/

4 Recordemos que el título que inicialmente Bolaño imaginaba para la novela corta que terminó siendo Nocturno de Chile era Tormenta de mierda. La propuesta fue rechazada por Jorge Herralde y Bolaño fue convencido de encontrar un título «más comercial».

5 Será nuevamente utilizado por los editores de Anagrama para titular el compendio póstumo de poesías publicado en 2007, La universidad desconocida.

6 https://www.pagina12.com.ar/diario/suplementos/radar/ subnotas/4753-799-2008-08-10.html

7 La escena del «interrogatorio retórico» se duplicará y se hará aún más hiperbólica en su erudición fuera de lugar al inicio de la tercera parte de la narración, «Los desiertos de Sonora» (1976), cuando Belano, Lima, Lupe y García Madero se encuentren ya fuera del DF, en el Impala robado a Quim Font: «Para entretener a mis amigos les hice algunas preguntas delicadas, que también son problemas, enigmas (sobre todo en el México literario de hoy), incluso acertijos» (681). A su vez, el interrogatorio será contestado por Lupe, que retará a los viajeros del Impala en torno a su extenso bagaje lexical proveniente del español mexicano callejero: prix, muy carranza, lurias, jincho, la grandiosa, macha chaca, rufo, manicure, dar cuello, dar caña, dar labiada, de empalme, chavo giratorio, coprero, echar pira, etcétera. 
8 De hecho, la anécdota, según algunos testimonios infrarrealistas, remeda un verdadero enfrentamiento que tuviera Mario Santiago en el taller dictado por Juan Buñuelos en la rectoría de la UNAM entre 1973 y 1974, frente a la negativa de este a sustituir las «críticas silvestres» ejercidas tanto por él como por los demás asistentes, por una «instrucción más formal», es decir, «estudiar a los clásicos, el Siglo de Oro de la literatura española, los cánones de la versificación, las vanguardias del siglo XX, etcétera» (Méndez Estrada:17).

9 Nuevamente acá encontramos una de las tantas correspondencias entre biografía y ficción que moldean la obra de Roberto Bolaño. El relato del acercamiento al libro de Louÿs se repite casi textualmente en la entrevista que le hiciera Fernando Villagrán para el programa televisivo chileno Off the record: «lo compré porque pensaba que era pornografía» (https://www.youtube.com/watch?v=qNhTTqu5Vsw). Igualmente, en el cuento «El gusano», incluido en Llamadas telefónicas
(2003), se cuenta la historia de un joven que escapa de clases para leer los libros robados de las librerías del DF.

10 Como acabamos de ver, la imantación producida por el poema de Lima que concentra el afecto que potenciará la manada será replicada por García Madero, quién obtendrá gracias a sus propias creaciones los favores de Brígida, de Rosario y quizás también de María Font, todas ellas público de sus poemas. A su vez, será en la «boda-contranatura» del caporal violado y luego violador de Rimbaud cuando Ulises Lima trazará la filiación que lo colocará a él como mexicano en contagio directo de la tradición de la vanguardia que coloca al poeta francés como su fundador.

11 En este sentido, varios estudios convienen en leer Los detectives salvajes bajo la clave de la novela de iniciación (Bildungsroman) o novela de artista (Kunstelroman). Tal es el caso de Espinosa (2014).

\section{Referencias}

Aristóteles (2007). Ética nicomáquea. Barcelona: Biblioteca Clásica Gredos.

Bolaño, R. (Ed.) (1979). Muchachos desnudos bajo el arcoíris de fuego. México: Editorial Extemporáneos.

Bolaño, R. (1996). La literatura Nazi en América.

Bolaño, R. (2003). Llamadas telefónicas. Barcelona: Anagrama.

Bolaño, R. (2007). La universidad desconocida. Barcelona: Anagrama.

Bolaño, R. (2010). Los perros románticos. Barcelona: Acantilado.

Bolaño, R. (2013). Entre paréntesis. Barcelona: Anagrama.

Bolaño, R. (2017). Los detectives salvajes. Barcelona: Penguin Random House Grupo Editorial.

Conde Soto, F. (2015). Los afectos como efectos del lenguaje sobre el cuerpo: de las pasiones de Aristóteles a los afectos en la teoría psicoanalítica de Freud y Lacan. Daimon. Revista internacional de Filosofía, (65), 119-132.

Deleuze, G. y Guattari, F. (2002). Mil mesetas. Capitalismo y esquizofrenia. Valencia: Pre-Textos.

Espinosa, P. (2014). Bildungsroman y modernidad en Los detectives salvajes. INTI. Revista de Literatura Hispánica, (79/80), 137-149.

Lowry, M. (1997). Bajo el volcán. Barcelona: Tusquets.

Manzoni, C. (Ed.) (200o). Dictamen del Jurado del premio Rómulo Gallegos. Roberto Bolaño: la escritura como tauromaquia. Buenos Aires: Corregidor.

Moraña, M. (2012). Postscríptum. El afecto en la caja de herramientas. En Moraña, M. y Sánchez Prado, I.M. (Eds.). El lenguaje de las emociones. Afecto y cultura en América Latina. Madrid: Hispanoamericana/Vervuert.

Paz, O. (1972). El arco y la lira. México: Fondo de Cultura Económica.

Piglia, R. (2001a). Respiración Artificial. Barcelona: Anagrama.

Piglia, R. (2001b). Crítica y Ficción. Barcelona: Anagrama.

Piglia, R. (2016). Los diarios de Emilio Renzi. Los años felices. Barcelona: Anagrama. 
Ribeyro, J.R. (2002). La tentación del fracaso. Barcelona: Seix Barral.

Ribeyro, J.R. (2012). La caza sutil y otros textos. Un desaprensivo paseo entre libros y autores. Santiago de Chile: Universidad Diego Portales.

Sarlo, B. (2005). Tiempo pasado. Cultura de la memoria y giro subjetivo: una discusión. Buenos Aires: Siglo XXI.

Villagrán, F. (1999). Entrevista de Fernando Villagrán a Roberto Bolaño. En el programa televisivo Off the record. https://www.youtube.com/watch?v=qNhTTqu5Vsw

Zambra, A. (2012). La poesía de Roberto Bolaño. En No leer. Santiago de Chile: Ediciones Universidad Diego Portales, Colección Huellas, 109-117. 